\title{
Gender Based Reproductive And Sexual Health Among Urban Adolescent Students in South India.
}

\author{
Varalakshmi Manchana, \\ ${ }^{I}$ School Of Medical Sciences, University Of Hyderabad, India.
}

\begin{abstract}
Adolescence is a transitional stage in human life. Adolescents are neither adults nor children and their physical and psycho social needs are unique, hence they experience great deal of confusion in taking right decisions. Adolescence range between the ages of ten to nineteen years and is a stage of behavioral and attitude formation. Awareness and adequate guidance to adolescents in appropriate time helps them to adopt healthy behaviors. If they are not well guided, they are likely to experiment with risky behavior that could harm them and others. Aim: The study aimed to assess the Knowledge on reproductive and sexual health (RSH) and Gender perceptions in school going adolescents. Methodology: Adolescent students between age group of 13 18 years $(N=150)$ were selected by random sampling. Single group pre - posttest design was used in the study. Structured questionnaire on identification data, gender attributes and sexual and reproductive health was introduced pre and post intervention. Findings: Pre assessment reveals thirteen percent of students with high gender equality scores and 52\% with moderate and $25 \%$ with low gender equitable scores. Post assessment shows enhancement in higher gender equality scores to $78 \%$ and $22 \%$ with moderate scores. $56 \%$ of girls and $32 \%$ of boys have reported experience of some sort of violence and $12 \%$ of them denied of experiencing any sort of violence. Conclusion: Gender balanced approach in child care and education is the need of the hour. Parents, Teachers and health professionals need to understand the delicacy in dealing with adolescent needs and adopt Gendered attitude and educate them healthy behaviors with rationale for sexual and reproductive health.
\end{abstract}

Keywords: Adolescents, Reproductive health, Sexual health, Gender perceptions, and Gender based violence.

\section{Introduction}

Adolescence is a transitional stage in human life. Adolescents are neither adults nor children and their physical and psycho social needs are unique, hence they experience great deal of confusion in taking right decisions. Adolescence range between the ages of ten to nineteen years and is a stage of behavioral and attitude formation. Awareness and adequate guidance in appropriate time helps them to adopt healthy behaviors. If they are not well guided, they are likely to move towards risky behaviors that could harm them and others. During this crucial period, a child undergoes biological transition, characterized by puberty, related changes in physical appearance and attainment of the reproductive capability, psychological or cognitive transition, which reflects an individual's thinking and social transition, which is related to rights, privileges and responsibilities of an individual $^{1}$. Rapid physical, physiological and psychosocial development of this age may lead to the experience of varying situations of risk. Adolescents prefer to develop relations beyond the family and may get attracted towards the opposite gender. They are more inventing and exploring in attitude and behaviors. If they are not well guided, they are likely to experiment with risky behavior that could harm them and others. It is a stage of behavioral and attitude formation. Attitudes formed in this stage are difficult to change. Attitudes and behaviors towards gender role and gender specific behavior and responsibilities in relation to the society are formed at this stage $^{2}$. It is very essential to initiate measures to shape their attitudes and transform behaviors. Biologically determined gender characteristics are universal, social difference and gender roles are learned and acquired. To reduce gender based violence and improve gender equality, the behavioral change must start with adolescents ${ }^{3}$.

\section{Background/Significance of the Study:}

Adolescent girls are more vulnerable due to socio-cultural practices and family patterns especially in the developing countries like India. They comprise 47\% of adolescent population. About $20 \%$ of total adolescent female population is married before the age of 15 years are already mother ${ }^{4}$. Although youth are healthier and better educated than ever before, yet vulnerabilities persist, and evidence suggests that healthy transition of adolescents to adulthood is not happening. 29\% of married young women initiated childbearing before 18 yrs. $9 \%$ of young women who reported engaging in pre-marital sex experienced a pre-marital pregnancy $^{5}$. Every year $1 / 3$ of all abortions performed on adolescent girls are unsafe abortions. Yyoung women (15-24 years) account for $46 \%$ of maternal deaths, while they account for $28 \%$ of non-maternal deaths. $25 \%$ of girls aged 13-14 reported having experienced of physical violence and $32 \%$ of girls and $4 \%$ of boys had sexual 
violence. Although youth are healthier and better educated than ever before, yet vulnerabilities persist, and evidence suggests that healthy transition of adolescents to adulthood is not happening.

Public health challenges associated with adolescent reproductive and sexual health and gender attitudes include raising teenage pregnancy, unsafe abortions, gender violence, sexually transmitted infections and rapidly increasing HIV infections in younger age. Adolescent population prepares the individual for an adult life. In the past few years, the growing evidence around gender attitudes, reproductive and sexual behavior patterns of the younger generation reveals the persistence of gender bias worldwide and inadequate addressing of RSH issues of the adolescents ${ }^{2,4,6} .30 \%$ of India's population (327 million) is in the age group of 10-24yrs (WHO 2007) . $^{2}$ $30 \%$ of women in the age group of 15-19yrs have had a live birth by 19yrs (NFHS3). $60 \%$ of girls in the age group of 15-19yrs were anemic (NFHS-3). Anemia is a contributing factor for age specific female mortality. $50 \%$ of children in India have reported same form of sexual abuse (Mother and Child Development 2007), among them 53\% victims were boys. Reproductive and sexual health is a major area of concern as the adolescents do not have adequate awareness and knowledge about it.

Information on issues related to gender norms, sexual and reproductive health remains inadequate to young people's needs. Adolescent health services remain inaccessible, unaffordable, judgmental and of indifferent quality ${ }^{8}$. Transforming the attitudes of adolescents towards developing healthy behaviors will be having an inter-generational impact. A study discusses about the association between menstrual hygiene maintenance and education, socio economic status, Knowledge prior to menarche, accessibility to water and bathroom facilities and menstrual disorders ${ }^{9}$. Inadequate knowledge on Reproductive and sexual health may result in to indulging in pre marital sex at an early age, increasing the incidence of teenage and unwanted pregnancies, miscarriages, transmission of STDs, HIV and so on. The present study evaluates the knowledge on reproductive and sexual health and Gender perceptions among urban adolescent students of the selected school from Hyderabad.

Aim

The study aims to assess the knowledge on Reproductive and Sexual health and gender perceptions among urban adolescent students.

\section{Objectives}

1. To Assess the Knowledge on sexual and Reproductive health among adolescent students between the age group of 13 to 18 years.

2. To measure the gender perceptions among adolescent students.

3. Develop and administer gender based sexual and reproductive health educational intervention program among the subjects

4. Evaluating the educational intervention in comparison to pre and post test scores.

\section{Methodology}

A Quasi experimental, Pre - Post test single group design was chosen for the study to assess the Knowledge on Gender based Sexual and Reproductive health and the effectiveness of the ARSH (Adolescent Reproductive and Sexual Health) educational intervention on knowledge regarding Gender based Sexual and Reproductive health among adolescent students(n=150) ( 79 Girls and 71 Boys) students from grade $8^{\text {th }}$ to $12^{\text {th }}$ standard, between the age-group of 13-18yrs, studying in a Government school, Hyderabad. Students willing to participate in the study were selected by simple random sampling after securing necessary institutional approvals. An interviewer assisted structured questionnaire was used to measure;

1. Reproductive and sexual Health

2. Gender attributes, Role and responsibilities

3. Gender based violence;

Based on the students' learning needs, structured education program was developed and validated. The tool was validated by the subject experts and the reliability of the tool was obtained by the Test- retest method. The subject's first and repeated scores were compared by Coefficient of correlation method. A value of $r=0.96$ was obtained, indicating the reliability of the tool. Single group Pre test- Post test design was used.

\section{$\mathrm{O} 1 \mathrm{X} \quad \mathrm{O} 2$}

The Pre-test and Post-test scores were compared to evaluate the effectiveness of the ARSH educational intervention.

Inclusion criteria:

- Adolescent students from $8^{\text {th }}$ to $12^{\text {th }}$ standard between the age group of 13 to 18 years

- Adolescent students who are willing to participate in the study.

Exclusion criteria: 
- Adolescent students who are not available during the data collection period

- Adolescent students who are with difficulty to understand and/or with any mental Illnesses.

Ethical approval was secured from the institutional ethical committee. Assent from the students and written informed consent from the Parent/ guardian was secured before initiating the study.

Tools used:

- Interviewer assisted, Structured questionnaire on Reproductive and sexual health; which contain 40 questions. The right answer is scored ' 1 ' and the wrong answer was given ' 0 '.

- Structured questionnaire on perceptions related to Gender attributes, gender role and relations; containing 20 questions.

- Structured questionnaire on perceptions related to Gender based violence, which contains 15 questions. Gender equality related attitudes were measured by scoring; Agreed '0' (gender biased response); Not sure '1' (neutral); Disagree'2' ( gender balanced responses)

\section{Results}

Among the total $79(53 \%)$ were girls and 71(47\%) were boys. Majority of the students were having adequate knowledge about the puberty changes in self and in the opposite sex such as increase in height, change in voice, breast development, and growth of facial hair, growth of hair in private parts, onset of menstruation in girls, etc. Adolescent students feel hesitant to seek information from teachers and parents. They are willing to take help from teachers but teachers were not adequately equipped with knowledge nor feel comfortable to discuss issues related to reproductive and sexual health with students.

The present study reveals that $52 \%$ of the boys and $63 \%$ of the girls have reported some or the other sort of reproductive health issues, among them $41 \%$ of the girls and only $5 \%$ of the boys have reported the issue to the closed family member for support.

Among the total girls, 74 of them attained menarche and in them nine of them reported of attaining menarche before 12 years of age, which is an area of concern for the reproductive health of young girl children, Pre assessment reveals thirteen percent of students with high gender equality scores and $52 \%$ with moderate and $25 \%$ with low gender equitable scores. Post assessment revealed enhancement in higher gender equality scores to $78 \%$ and $22 \%$ with moderate scores. $56 \%$ of girls and $32 \%$ of boys have reported experience of some sort of violence and $12 \%$ of them denied of experiencing any sort of violence. Students were asked about their experience of physical / verbal / emotional/ sexual abuse or violence at home or school or any other place, both as victims / and cause; and their responses were measured.

Table 1: Frequency and percentage distribution of subjects' total Pre and Post test Knowledge levels; $\mathrm{N}=150$

\begin{tabular}{|l|l|l|l|l|l|l|l|l|l|}
\hline S.No & Knowledge levels in & \multicolumn{3}{|c|}{ Pre test } & \multicolumn{3}{c|}{ Post test } \\
\hline \multirow{2}{*}{} & \multirow{2}{*}{ RSH } & \multicolumn{2}{|c|}{ Girls } & Boys & Girls & \multicolumn{2}{l|}{ Boys } \\
\cline { 3 - 10 } & & $\mathrm{n}$ & $\%$ & $\mathrm{~N}$ & $\%$ & $\mathrm{n}$ & $\%$ & $\mathrm{n}$ & $\%$ \\
\hline 1 & Below Average & 32 & 40.5 & 36 & 50.7 & 2 & 03 & 4 & 6 \\
\hline 2 & Average & 29 & 36.7 & 20 & 28.2 & 9 & 11 & 10 & 14 \\
\hline 3 & Above average & 18 & 22.8 & 15 & 21.1 & 68 & 86 & 57 & 80 \\
\hline 4 & Total & 79 & 100 & 71 & 100 & 79 & 100 & 71 & 100 \\
\hline
\end{tabular}

Findings of (Table 1) Knowledge scores revealed that the girls in above average category increased from $23 \%$ to $86 \%$ in the girls and post test scores. It was $21 \%$ to $80 \%$ in boys.

Table 2; Previous knowledge about Reproductive and sexual health information:

$$
\mathrm{N}=150
$$

\begin{tabular}{|l|l|l|l|l|l|}
\hline \multirow{2}{*}{ ITEM } & \multicolumn{3}{l|}{ Boys } \\
\cline { 3 - 6 } & & Girls & $\%$ & N & $\%$ \\
\hline \multirow{2}{*}{$\begin{array}{l}\text { Did you learn the information on RSH } \\
\text { before participating in the study }\end{array}$} & YES & 38 & 48.10 & 27 & 38 \\
\cline { 2 - 6 } & NO & 41 & 51.90 & 44 & 61.9 \\
\hline Total & & 79 & $100 \%$ & 71 & $100 \%$ \\
\hline
\end{tabular}

Knowledge regarding Reproductive and sexual health was reported as $38 \%$ girls and $27 \%$ boys, stated having exposure to information before participating in the study. 
Gender based Reproductive and Sexual Health among urban adolescent students in South India.

Table 3: Awareness about Menstruation and Menstrual Hygiene among adolescents

\begin{tabular}{|c|c|c|c|c|c|}
\hline & & & & & \\
\hline \multirow[t]{2}{*}{ S.NO } & \multirow{2}{*}{$\begin{array}{l}\begin{array}{l}\text { Awareness } \\
\text { and Hygiene }\end{array} \\
\text { about Menstruation }\end{array}$} & \multicolumn{2}{|c|}{ GIRLS } & \multicolumn{2}{|c|}{ BOYS } \\
\hline & & $\mathbf{n}$ & $\%$ & $\mathbf{n}$ & $\%$ \\
\hline 1 & YES & 52 & 66 & 32 & 45 \\
\hline 2 & NO & 27 & 34 & 39 & 55 \\
\hline 3 & Total & 79 & 100 & 71 & 100 \\
\hline
\end{tabular}

The findings (Table 3 ) reveal that $2 \%$ of the girls are not aware of menstrual hygiene before attaining menarche. Thirty nine percent of the boys stated, they have no understanding about menstrual hygiene. Those who were aware of menarche, mostly they were informed by their mothers, before they had their first period. A large majority did not know the biomedical reason for menstruation.

$\mathrm{N}=150$

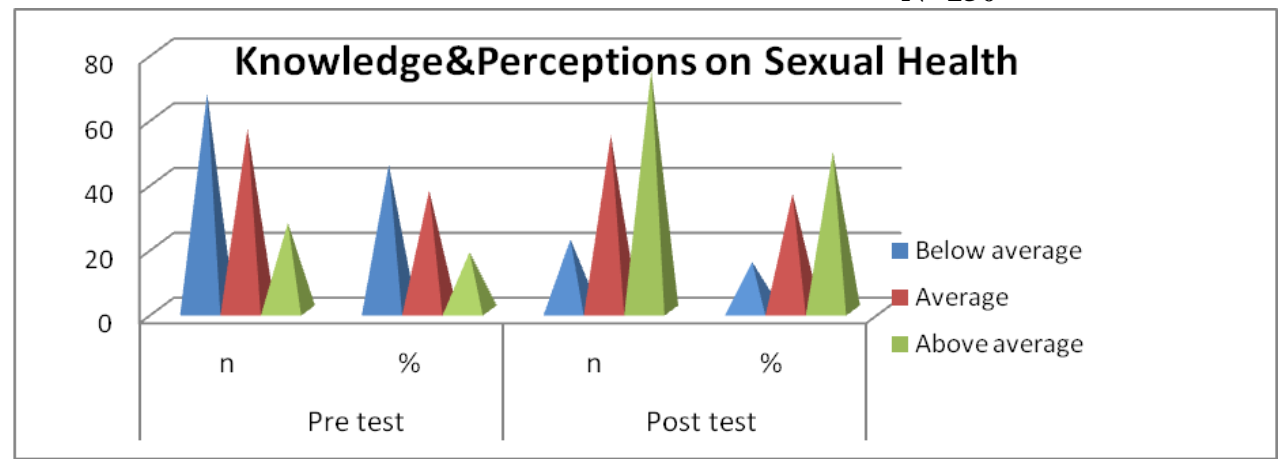

Figure 1: Pre \& Post test Knowledge levels on Sexual health and perceptions on Sexual health behaviors;

The knowledge distribution related to sexual health among adolescent students (Fig.1) shows enhancement of knowledge from $21 \%$ to $78 \%$ in the above average level.

Table 4: Frequency distribution of Gender equality perceptions in Adolescent students;

$\mathrm{N}=150$

\begin{tabular}{|l|l|l|l|l|l|l|}
\hline \multirow{2}{*}{ Gender Perception } & Scores & Girls & Boys & Total & \\
\cline { 2 - 8 } & Pre & Post & Pre & Post & Pre & Post \\
\hline Higher & 8 & $\mathbf{5 6}$ & 4 & $\mathbf{4 8}$ & 12 & 104 \\
\hline Moderate & 31 & 18 & 22 & 10 & 53 & 28 \\
\hline Low & $\mathbf{4 0}$ & 5 & $\mathbf{4 5}$ & 13 & 85 & 18 \\
\hline Total & 79 & 79 & 71 & 71 & 150 & 150 \\
\hline
\end{tabular}

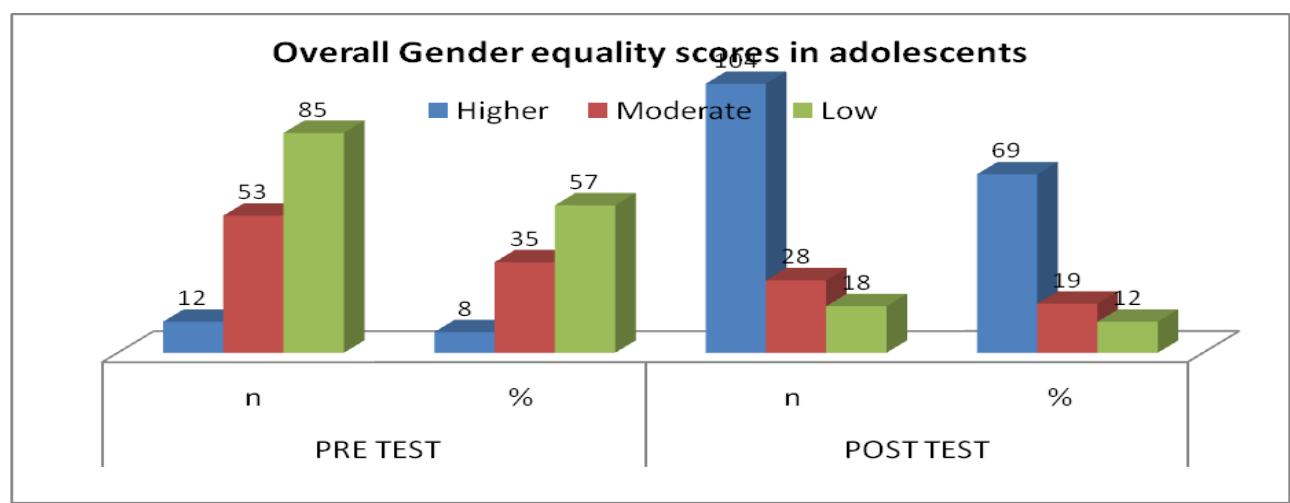

Fig.2: Overall Gender equality scores in adolescent students;

Among the total(Table.4\& Fig.2) students 85 of them were found to be with low scores on gender equality, which has been recorded as $18 \%$ in the lower perceptions of gender equality and $104(69 \%)$ of them were with high gender equality scores in the post assessment scores. 


\section{Adolescents reported of having experienced some sort of violence}

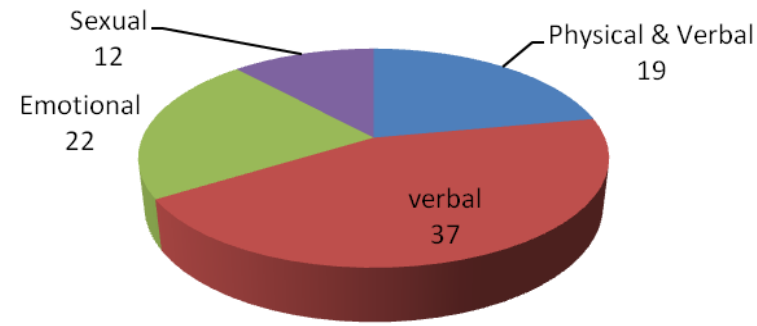

Fig.3: Frequency distribution of adolescents, who have reported of Gender based Violence:

Among the total $(n=150)$ students, $60 \%$ of them $(n=90$; Girls: $(n=54)(68 \%)$; Boys; $n=36(51 \%)$; (Fig.3) have reported of experiencing some sort of gender based violence. The Figure2, reflects the type of violence reported by the $(n=90)$ students. Among the reported students, $48 \%$ of them said they have never reported of their experiences to any one before participating in the study due to not feeling a confidential member to seek help.

$40 \%$ among the total students stated that they have never experienced any sort of violence.

Table 5: Students’ Distribution according to Gender equality scores;

\begin{tabular}{|l|l|l|l|l|l|l|}
\hline \multirow{2}{*}{ Scores } & Girls & Boys & \multicolumn{2}{l|}{ Total } \\
\cline { 2 - 7 } & Pre & Post & Pre & Post & Pre & Post \\
\hline Higher & 9 & 13 & 5 & 48 & 13 & 114 \\
\hline Moderate & 30 & 52 & 21 & 17 & 52 & 28 \\
\hline Low & 40 & 85 & 45 & 6 & 85 & 8 \\
\hline Total & 79 & 150 & 71 & 71 & 150 & 150 \\
\hline
\end{tabular}

Gender equality Scores ranges from a minimum of 13(8.66) to 114 (75.99) towards higher gender equality perceptions among adolescent students. Only 8 of them remain to be recorded with lower gender equality perceptions in the post assessment.

Table.6; Percentage distribution of adolescent students who reported experience of Violence:

\begin{tabular}{|l|l|l|l|}
\hline Type of Violence & $\begin{array}{l}\text { Total } \\
\%\end{array}$ & $\begin{array}{c}\text { Girls } \\
\%\end{array}$ & $\begin{array}{l}\text { Boys } \\
\%\end{array}$ \\
\hline Physical & 15 & 40 & 60 \\
\hline verbal & 30 & 50 & 50 \\
\hline Emotional & 15 & 60 & 40 \\
\hline Sexual & 20 & 70 & 30 \\
\hline
\end{tabular}

Students responses revealed about experience violence $=70 \% ; \quad$ Reported $=48 \%$ Students reported not experienced any sort of violence was: 12\% (Table.6).

Table.7; Frequency and Percentage distribution of pre-post test Gender attribute scores in adolescent students; $\mathrm{N}=150$

\begin{tabular}{|l|l|l|l|l|l|l|l|l|}
\hline \multirow{2}{*}{ S.No \& Characteristic } & \multicolumn{4}{|c|}{ Pre test } & \multicolumn{5}{c|}{ Post test } \\
\cline { 2 - 11 } & Girls & Boys & Girls & \multicolumn{2}{l|}{ Boys } \\
\hline & $\mathrm{n}$ & $\%$ & $\mathrm{n}$ & $\%$ & $\mathrm{n}$ & $\%$ & $\mathrm{n}$ & $\%$ \\
\hline 1.Gender biased & 21 & 26.6 & 29 & 40.8 & 8 & 10.1 & 3 & 4.2 \\
\hline 2.Gender balanced & 52 & 65.8 & 39 & 54.9 & 64 & 81 & 65 & 91.5 \\
\hline 3. Uncertain & 6 & 7.6 & 3 & 4.2 & 7 & 8.86 & 3 & 4.2 \\
\hline
\end{tabular}

It indicates remarkable improvement (Table 7$)$ in the gender balanced responses $(91.5 \%$ in Boys and $81 \%$ in girls); after the education, which is comparatively more in boys.

\section{Discussion}

Traditional perception and disgrace perceived in related to discuss about reproductive and sexual health issues with children and/or students would leave young people ill informed and unlikely to receive parental 
guidance in relation to sexual matters, information on issues related to growing up remains inadequate and confusing to young people's needs. Adolescent health services remain inaccessible, judgmental and indifferent in quality and unfriendly (UNPF India, 2007). Despite 35\% of the population being in the 10-24 age group, the health needs of adolescents have not been addressed adequately; particularly the reproductive health needs are often misunderstood, unrecognized or underestimated ${ }^{11,1213}$, reported in studies on improving Reproductive health among Rural college youth, states that Boys had more liberal attitudes towards premarital sex as compared to the girls. In the study about $11 \%$ of boys and $1 \%$ of girls reported to have experienced premarital sex. Adolescence is the right age of attitude formation. Adequate Information \& Education on adolescent reproductive \& sexual health (ARSH) and gender concepts helps adolescents to develop gender balanced attitude and adopt healthy behaviors. Proper health education on ARSH equips them with right knowledge, practices in a gender balanced way of thinking. The study findings reveal the inadequacy in adolescent awareness on RSH and the need for education, counseling and the demand for replicable, sustainable model for adolescent friendly, engendered Reproductive and Sexual health education.

Family being the first social unit, adolescents accepts the prescribed gender roles at home. Directly or indirectly parents influence their attitude formation towards gender norms and reproductive health behavior. India is a country with values and culture greatly influencing the family system, the patriarchic system with a male child preference may grew in the mind sets of children with glorification of man and subordination of the woman. To minimize the gender inequality and gender based violence, creating boys and girls with equitable contribution in the society with proper gender norms should begin early in adolescence which contributes to the healthy development of the society.

The present study findings support the need for school based education and counseling for the right development of Adolescent friendly and gender based sexual and reproductive health education and information is proved to be the priority need. Though reproductive system and reproduction were part of the syllabus those chapters are usually given a passing reference or left for self learning, as teachers themselves were apprehensive and were uncomfortable in teaching these topics in the classrooms. Teachers felt ill equipped to discuss reproductive health topics with their students. They acknowledge the need but not all are in favor of providing sex education to school children. According to them the community in the rural background would not be comfortable with such education being imparted to students in the schools and they also feared that increased knowledge might encourage adolescents to indulge in experimentation. Sexuality is a natural and intrinsic part of an individual's personality and needs to be nurtured and developed like all other facts of life. The inhibition about discussing and expressing themselves on sexual health issues makes them discourage the children from any form of sexual expression and encourage them to hide their sexuality. In the Indian socio-cultural setting sex is a taboo, and hence the society does not provide them with channels for being appropriately educated in this area ${ }^{7}$. The adolescents generally do not get adequate advice and guidance regarding, various aspects like puberty, menarche, reproductive health, from their parents and teachers or health professionals. Adolescents were agreeable to learn about RSH and expressed interest to avail the adolescent friendly school health services.

\section{Conclusion}

Regardless of the Government emphasis on adolescent reproductive and sexual health, the area is still left under covered both in the health facilities and in schools. Knowledge and discussion about reproductive and sexual health is considered to be a sensitive issue and especially the growing adolescents are left unattended with their learning demands. Thus they are not prepared to understand and follow the reproductive and sexual health behaviors \& practices. Inadequate knowledge may result in to confusion and risk of potential threats of reproductive illnesses and vulnerabilities among young adolescents. Most of them expressed a desire to know more about reproductive health as part of the school curriculum. Relatively less social support was reported for boys as compared to girls, in terms of reproductive changes occurring in body. Adolescents were well motivated and agreeable to listen and to learn about RSH and expressed interest to avail the adolescent friendly school health services. Adequate Information \& Education on ARSH and gender concepts helps adolescents to equip with right knowledge, practices in a gender balanced manner. The study findings demonstrate a very sharp improvement in the knowledge levels and attitudes towards gender equality both in girls and boys after introducing the structured education intervention on gender sensitive $\mathrm{RSH}$.

\section{Limitations and Recommendations}

Retention of information might be greater if follow up reinforcement would be enhanced for a period of 6 months and 12 months. A realistic attitudinal and behavioral transformation can be studied in the follow up study. 


\section{Acknowledgements}

The author wish to acknowledge the support of the School Principal for his support in lending the permission for conducting the study and the junior faculty assisted in data collection and would extend special appreciation to all the student participants of the study.

\section{Funding Statement:}

This research received no specific grant from any funding agency in the public, private or non-profit sectors.

\section{Conflicts of Interest:}

No Conflict of interest has been declared by the author.

\section{References}

[1]. Steinberg L, Autonomy, conflict and harmony in the family relationship. In At the threshold: The developing adolescent Edited by: Feldman, Elliot G. Cambridge, Havard University; (1990) 255-276.

[2]. Lundgren R, Beckman M, Prasad Chaurasiya S, Subhedi B, Kerner B, Whose turn to do the dishes? Transforming gender attitudes and behaviours among very young adolescents in Nepal. Gend Dev; 21 (2013) : 127_45.

[3]. Dunkle KL, Jewkes RK, Brown HC, Gray GE, McIntryre JA, Harlow SD, Gender-based violence, relationship power, and risk of HIV infection in women attending antenatal clinics in South Africa. Lancet; 363 (2004); 1415-21.

[4]. Haberland, N., \& Rogow, D. In \&Promoting Healthy, Safe, and Productive Transitions to Adulthood Brief no.22. New York, NY: (2007); Population Council.

[5]. Britto MT, Klostermann BK, Bonny AE, Altum SA, Hornung RW. Impact of a school-based intervention on access to healthcare for underserved youth. J Adolesc Health,29 (2001); 116-125.

[6]. Verma, R., Pulerwitz, J., Mahendra, V., Khandekar, S., Singh, A. K., Das, S., et al., Promoting gender equity as a strategy to reduce HIV risk and gender-based violence among young men in India. Washington, DC(2008): Population Council.

[7]. WHO. The sexual and reproductive health of younger adolescents. Research issues in developing countries. Geneva: WHO. (2011)

[8]. Tolman DL, Striepe MI, Harmon T. Gender matters: constructing a model of adolescent sexual health. J Sex Res (2003); 40:4-12

[9]. Agampodi B Suneth, Thilini C Agampodi and Piyaseeli UKD. Adolescent perception of reproductive health care services in Srilaka, BMC Health services Research, (2008); 8:98.

[10]. UNICEF. State of the World's Children report, The Double Dividend of Gender Inequality; (2007).

[11]. B.N. Joshi, S.L. Chauhan, U.M. Donde, et al, Reproductive Health Problems and Help Seeking Behavior Among Adolescents in Urban India, Indian Journal of Paediatrics,73(2),(2006), 509-513.

[12]. Karim, A. M., Magnani, R., Morgan, G., \& Bond, K. Reproductive health risk and protective factors among unmarried youth in Ghana. International Family Planning Perspectives, 29(1) (2003) ; 14-24.

[13]. Mohan Ghule, Balaiah Donta, Correlates of sexual behaviour of rural college youth in Maharashtra, India, Eastern Journal of Medicine 16 (2011)122-132. 